\title{
PROSES KREATIF TARI LENGGASOR DI SANGGAR WISANGGENI KABUPATEN PURBALINGGA, BANYUMAS
}

\author{
Wien Pudji Priyanto Djuli Pitoyo \\ Fakultas Bahasa dan Seni, Universitas Negeri Yogyakarta \\ E-mail:wienpudji@uny.ac.id
}

\begin{abstract}
Abstrak
Penelitian ini bertujuan untuk mendeskripsikan proses kreatif dalam penciptaan tari Lenggasor di Sanggar Wisanggeni di Kabupaten Purbalingga, Banyumas. Objek penelitian adalah Proses Kreatif Tari Lenggasor di Sanggar Wisanggeni Kabupaten Purbalingga. Subjek penelitian yaitu koreografer gerak tari, pencipta gendhing atau iringan, penari, dan salah seorang staf dari dinas kebudayaan Kabupaten Purbalingga. Susianti, S.Sn. sebagai seorang koreografer tari Lenggasor memiliki ide dan gagasan untuk mengembangkan tari Lengger dengan warna, rasa dan bentuk yang baru yang lebih dinamis dan atraktif sehingga mampu memberikan apresiasi kepada masyarakat. Proses kreatif muncul ketika pencipta memiliki kegelisahan untuk dapat mengembangkan lebih jauh materi yang sudah ada. Dalam penciptaan karya seni tari Lenggasor pencipta secara otomatis akan dipengaruhi oleh latar belakang pendidikan atau keinginan ide dan kreativitas untuk mengembangkan tari Lengger menjadi sebuah karya yang baru. Proses kreatif penciptaan tari Lenggasor tidak lepas dari tahapan eksplorasi, improvisasi, evaluasi, dan pembentukan. Tari Lenggasor tercipta atas dasar pengembangan gerak tari Lengger yang sudah ada sejak zaman dahulu yang sampai saat ini tetap hidup sebagai khasanah kekayaan seni tradisional di Banyumas.
\end{abstract}

Kata kunci: proses kreatif, Tari Lenggasor, Sanggar Wisanggeni.

\section{CREATIVE PROCESS OF LENGGASOR DANCE IN WISANGGENI CLUB IN PURBALINGGA DISTRICT, BANYUMAS}

\begin{abstract}
The purpose of this research is to describe the creative process in the creation of Dance Lenggasor in Wisanggeni club in Purbalingga district, Banyumas. The object is the creative process of Lenggasor dance, and the subject are the choreographer, gending composer, dancer, and one of the staff of Cultural Department of Purbalingga district. Susianti, S.Sn is the choreographer of Lenggasor dance who has the idea to create lengger dance with new different color, sense, and movement which is more dynamic and attractive. Thus, it is dedicated to the society. The creativity rises up when the motivated thought drives her to the unstoppable felling to create this material with further innovation. In the creative process of Lenggasor dance the educational background, idea, and creativity to compose a new dance or adaptable one to increase it become more attractive. The steps of creation are exploration, improvisation, evaluation, and composition. Lenggasor Dance is created based on the moves of Lengger dance which has existed sinced very long time ago, and it enriches the culture of Banyumas Art.
\end{abstract}

Keywords: Creative process, Lenggasor Dance, Wisanggeni Club. 


\section{PENDAHULUAN}

Purbalingga merupakan bagian dariwilayah Banyumas yang memiliki jenis dan bentuk kesenian yang beraneka ragam, antara lain, Ujungan, Begalan, Aplang, Lengger, Buncis, Jemblung, Dhaeng, Dhames, Sholawatan, Ebeg, Ronggeng, Sintren, Ketoprak, Wayang Kulit, karawitan calung, gamelan, angklung, thek-thek kenthong, dan sebagainya. Dari sekian banyak kesenian yang ada, seni Lengger merupakan salah satu jenis kesenian tradisional yang hidup dan berkembang di berbagai desa maupun kota Purbalingga. Hal ini menunjukan bahwa masyarakat Purbalingga peduli dan menyenangi kesenian tersebut. Bahkan banyak bermunculan grup atau sanggar seni yang mengembangkan seni Lengger menjadi bentuk sajian yang berbeda, modern, inovatif, dan atraktif.

Salah satu sanggar seni tersebut adalah sanggar "Wisanggeni" di kabupaten Purbalingga yang sampai saat ini dikenal sebagai sanggar yang kreatif dan produktif untuk mencipta tarian baru yang berlatar belakang kesenian Lengger. "Tari Lenggasor" adalah salah satu tarian yang diciptakan atau diproduksi oleh sanggar seni Wisanggeni dan sudah berkali-kali pentas dalam berbagai event baik di tingkat lokal, nasional, bahkan internasional serta memperoleh kejuaraan dalam mengikuti lomba maupun festival. Kini tari Lenggasor tersebut menjadi salah satu ikon dan identitas budaya serta membawa nama Purbalingga dan Banyumas lebih dikenal oleh masyarakat lain di tingkat lokal, nasional, maupun internasional dengan segala bentuk pengembangan sesuai dengan dinamika perubahan zaman.

Tari Lenggasor diiringi karawitan Calung danjuga bisa dengan gamelan, bahkan campuran keduanya yang merupakan salah satu kesenian yang pengungkapannya melalui media gerak dan iringan/musik bambu (Calung), kostum atau pakaian, tata rias, tata pentas yang modern yang sangat dinamis dan atraktif.

Sal Murgiyanto (1977: 13) menyatakan bahwa proses kreatif adalah proses mengenal dan memahami segala sesuatu yang diteliti atau diamati dalam lingkungan sekitar untuk mampu memecahkannya tanpa berhenti. Sudarsono (1978: 21-36) elemen komposisi tari terdiri dari (a) Tema, (b) Gerak, (c) Musik iringan, (d) desain dramatik, (e) desain Lantai, (f) tata rias dan busana, (g) tempat pertunjukan.

Berdasar pendapat di atas maka proses kreatif itu penting keberadaannya sebagai salah satu langkah yang harus dilakukan oleh seorang kreator dalam mewujudkan karyanya. Tanpa ada proses kreatif maka karya tersebut tidak akan menarik, inovatif, dan atraktif dalam seni pertunjukan tari khususnya. Kreativitas seorang koreografer sangat dipengaruhi oleh pengetahuan, wawasan, pengalaman dan menerima saran, kritik dari berbagai pihak agar karya tersebut menjadi baik.

Lois Ellfeldt dalam Sumandyo Hadi (1983:1) mengatakan ciri-ciri orang kreatif adalah sebagai berikut, (a) Memiliki rasa ingin tahu, (b) Fasih dalam ide dan image, (c) Memiliki kepekaan cita rasa dan kekuatan melawan hal yang klise, (d) Memiliki keterlibatan, motivasi, dan penghayatan yang dalam. Seorang koreografer atau penata tari membutuhkan daya imajinasi yang tinggi dan keberanian, semangat, dan percaya diri serta siap menerima segala kritikan baik yang pedas maupun membvangun dari orang lain.

Dinas Pariwisata dan Kebudayaan Banyumas (2001:23) menyatakan bahwa seni Lengger calung adalah seni pertunjukan khas Banyumas yang dilakukan oleh penari wanita. Kata Lengger merupakan penggabungan dari dua kata yaitu Leng yang berarti lubang dan Jengger yang berarti mahkota/kepala alat kelamin pada laki-laki.

Ahmad Tohari dalam Ronggeng Dukuh Paruk menyatakan bahwa zaman dahulu di Banyumas ditarikan pada masa setelah panen sebagai ungkapan rasa syukur masyarakat kepada dewa yang telah memberikan rizki.

Tari Lenggasor dalam ide gagasannya berasal dari seni Lengger, disini sang koreografer mengembangkan ide kreatifnya untuk mengemas gerak, iringan, rias busana menjadi lebih menarik, inovatif dan atraktif sehingga penonton lebih menyenanginya. Pada dasarnya 
tari Lenggasor merupakan pengembangan dari seni Lengger yang hidup dan berkembang di daerah Purbalingga khususnya dan Banyumas pada umumnya. Sanggar Wisanggeni sebagai salah satu sanggar tari di Purbalingga telah berusaha mengembangkan dengan proses kreatifnya merubah seni Lengger menjadi tari Lenggasor yang lebih menarik lagi.

Kuntjaraningrat (1994: 211-212) masa sesudah panen adalah masa untuk bersuka ria bagi para petani maka pada saat itu para penari Lengger sibuk melayani pesanan untuk menari. Selanjutnya M Kodari (1991: 60) Lengger merupakan akronim dari leng dan jengger. Dikiranya penari itu leng (lubang) artinya wanita, ternyata Jengger (terjulur) artinya pria atau laki-laki. Dahulu tari Lengger dilakukan oleh kaum pria, karena aktivitas kesenian dilaksanakan pada malam hari bahkan sampai semalam suntuk sehingga jarang kaum perempuan yang mau bahkan dilarang untuk berkesenian.

Berikutnya Sumandyo Hadi (2003: 65) menyatakan tentang tahapan Koreografi meliputi (1) Eksplorasi, (2) Improvisasi, (3) evaluasi, dan (4) Forming/komposisi. Tahapan ini menjadi penting tatkala seorang koreografer menciptakan sebuah karya tari, langkah awal yaitu penjajagan atau eksplorasi yaitu pakah ide aatau gagasan tersebut dapat diwujudkan sebagai bentuk tarian. Kemudian tahap improvisasi yaitu kerja studio untuk mencoba menuangkan ide ke dalam gerakan, mencoba kemungkinan-kemungkinan agar dapat menemukan gerakan yang akan dijadikan bahan atau materi sebuah tarian. Tahap selanjutnya adalah Evaluasi yaitu menyeleksi gerakangerakan yang sekiranya dapat dijadikan materi gerak tari yang diciptakan. Tahap akhir yaitu komposisi tari yaitu mewujudkan, membentuk, atau menyusun ragam gerak yang sudah pasti menjadi ragam gerak yang dirangkai menjadi satu kesatuan yang utuh.

Berdasar pendapat di atas maka proses kreatif itu penting keberadaannya sebagai salah satu langkah yang harus dilakukan oleh seorang kreator dalam mewujudkan karyanya. Pemahaman pengetahuan, keilmuan, wawasan, dan pengalaman selama belajar di ISI Surakarta menjadikan seorang Susiati, S.Sn. sebagai koreografer atau pencipta berkeinginan untuk berkarya dan terus berkarya.

Hal ini tidak lepas dari Susianti, S.Sn. yang berperan sebagai pencipta atau koreografer dalam melaksanakan proses kreatif atau menyusun gerak, serta bentuk penyajian yang bagus. Fenomena di atas menarik untuk dilakukan kajian atau penelitian tentang proses kreatif tari Lenggasor di kabupaten Purbalingga Banyumas dan bagaimana bentuk penyajian serta tanggapan masyarakat terhadap tari tersebut dan apakah berdampak menjadi ikon atau identitas budaya khas Banyumas. Agar penelitian ini lebih terarah dan sesuai dengan harapan, peneliti memfokuskan penelitiannya pada "Proses Kreatif Pengembangan Tari Lenggasor di Sanggar Seni "Wisanggeni" Kabupaten Purbalingga" Banyumas Jawa Tengah.

\section{Rumusan Masalah}

1) Bagaimana proses kreatif perkembangan tariLenggasordisanggarseni"Wisanggeni”" Purbalingga Banyumas?

2) Bagaimanabentukpenyajian tariLenggasor yang sudah mengalami pengembangan koreografi saat ini.

\section{Tujuan Penelitian}

1) mendeskripsikan proses kreatif perkembangan tari Lenggasor di sanggar seni "Wisanggeni" Purbalingga Banyumas,

2) Mendeskripsikan bentuk penyajian tari Lenggasor di sanggar seni Wisanggeni kabupaten Purbalingga Banyumas.

\section{METODE}

Penelitian ini merupakan penelitian kualitatif dengan pendekatan deskriptif. Pelaksanaannya lebih banyak mendeskripsikan atau menguraikan hasil temuan dilapangan. Adapun langkah-langkah penelitian ini meliputi (1) penentuan seting penelitian, (2) subjek dan objek penelitian, (3) waktu penelitian, (4) analisis data penelitian dan (5) uji keabsahan data. Setting atau tempat penelitian tentang 
proses kreatif pengembangan tari Lenggasor ini dilaksanakan di sanggar Wisanggeni yang terletak di desa Bancar dan Kutasari Kabupaten Purbalingga Banyumas. Subjek penelitian tentang proses kreatif tari Lenggasor di sanggar Wisanggeni kabupaten Purbalingga adalah, pencipta/Koreografer garak tari Lenggasor, penata Iringan, penari, dan staf Dinas Kebudayaan Kabupaten Purbalingga. Objek penelitian adalah tari Lenggasor produksi sanggar Wisanggeni dari kabupaten Purbalingga Banyumas Jawa Tengah.

Analisis data dilakukan untuk mengkaji dan mengetahui setelah data data terkumpul selanjutnya dianlisis secaradeskripitifkualitatif. Langkah langkah dalam menganalisis data antaralain (1) Reduksi data, (2) Display data dan (3) Pengambilan kesimpulan. Uji keabsahan data peneliti menggunakan teknik Triangulasi sumber, yaitu pengecekan dan pemeriksaan data dari beberapa sumber informasi yang dapat dipertanggung jawabkan. Sumber informasi antaralain, Pencipta/Koreografer tari Lenggasor, Penata iringan tari, Penari dan personil dari Dinas Kebudayaan Kabupaten Purbalingga

\section{HASIL DAN PEMBAHASAN}

Berdasarkan hasil wawancara dengan Susiati, S.Sn. dan Wendo, (Agustus 2016) pada awalnya nama Wisanggeni diambil dari tokoh pewayangan yang bernama Wisanggeni. Singkat cerita tepatnya di tahun 2006 Dinas Kebudayaan Kabupaten Purbalingga yang saat itu dalam misi duta seni pelajar untuk Purbalingga di Banten menggarap sebuah tarian. Garapan tari ini digarap langsung oleh Susiati (Susi Hanan Fadila) dan penata musik/ketua sanggar Wisanggeni adalah Wendosetyono, S.Sn., yang keduanya merupakan lulusan ISI Solo. Mereka lulus tahun 1999 yang saat ini sebagai guru seni budaya di SMPN 1 Bobotsari) yang merupakan suami dan istri. (Wawancara, Jumat, 19 September 2016)

Saat pemenuhan administrasi ternyata diwajibkan untuk menggunakan nama group. Tetapi saat itu ternyata belum di beri nama oleh pihak kontingen hanya mengatas Namakan
Duta Seni Pelajar Purbalingga. Setelah pentas di Banten, lalu pentas lagi untuk lomba di Semarang pada acara Seni Pertunjukkan Rakyat (11 Agustus 2006), dan pada saat itu juga grup ini dinamakan Wisanggeni. Hal ini kemudian dipikirkan kembali oleh Susi dan Wendo. Teringat tentang nama wayang yang menjadi idola dan sering di idolakan, akhirnya saat itu juga grup kontingen dari Purbalingga dinamai Wisanggeni. Setelah berjalannya waktu, ditambah dengan kerap kali sering mengadakan pementasan, akhirnya muncul ide untuk mendirikan grup/sanggar tari. Hal ini didasari sikap empati dan sayang apabila grup tersebut hanya dipakai saat ada perlombaan saja.

Dari kejadian tersebut kemudian dirundingkan antara penabuh, penata tari dan koreografer untuk mendirikan sebuah sanggar. Munculah sebuah keputusan untuk mendirikan sanggar dan diberi nama Sanggar Wisanggeni dengan Wendosetyono sebagai pimpinan sanggar. Dalam perjalanannya sanggar ini terkenal di kalangan dinas dan kabupaten Purbalingga. Namun untuk pola latihannya belum begitu terstruktur, seperti bentuk latihan rutin untuk sanggar masih dalam perencanaan yaitu rencana hari jumat dan minggu pagi. Untuk lokasi pelatihan tari berada di dinas kebudayaan kabupaten Purbalingga.

Sanggar Wisanggeni sering mendapat kesempatan atau job dari dinas kebudayaan untuk mengikuti acara perlombaan atau pementasan yang notabene mewakili pemerintah kabupaten Purbalingga. Hal yang dilakukan Sanggar Wisanggeni adalah mengumpulkan para penari dari berbagai institusi pelajar kemudian mengadakan latihan yang dilaksanakan di dinas. Untuk para pengiring tari sudah tidak perlu mencari lagi dikarenakan dari pihak Sanggar Wisanggeni memiliki kelompok atau grup karawitan sehingga dapat dimanfaatkan sebagai personel pengrawit tari. Hal ini merupakan solusi yang dipakai, dikarenakan belum adanya mempunyai murid yang tetap. Mengapa belum memiliki murid tetap, dikarenakan dari pihak 
Susiati dan Wendo sendiri belum siap untuk menyediakan tempat lokasi untuk kegiatan pelatihan. Untuk tarian yang pernah diajarkan oleh Sanggar Wisanggeni kebanyakan adalah tari Ngoser, Lenggasor, Tetunggak dan Rongtek (kebanyakan gaya banyumasan).

\section{Proses Kreatif}

Tari yang diciptakan Susiati kebanyakan adalah tari kelompok. Namun untuk tarian yang paling digemari oleh masyarakat adalah tari Ngoser dan Lenggasor. Prestasi Sanggar Wisanggeni walaupun dengan keadaan yang seperti sekarang mampu meraih kejuaraan sbb: (1) Tari Rongtek mampu menjadi finalis 13 besar nasional "Parade Tari Nusantara" dan 5 besar untuk kategori "musik", (2) Tari Lenggasor menjadi juara 1 Nasional dalam Gebyar Budaya Wisata Nasional di JCC tahun 2011, (3) Juara 3 tari garapan tingkat Jawa Tengah (Tari Lenggasor)

Berbagai event yang berkaitan dengan tari-tari garapan Sanggar Wisanggeni sendiri sering mengeluarkan tari gaya Banyumasan untuk tampil dalam festival tari. Kebanyakan tari yang dipentaskan adalah tari Lenggasor yang kerap kali dipakai untuk pentas bil ada acara penting di pemerintah daerah kabupaten Purbalingga.

\section{Tari Lejeg}

Pada awal mulanya nama tarian ini adalah bukan Lenggasor, melainkan Lejeg (Lengger Jejeg). Terinspirasi dari tarian sebelumnya yang bernama tari Ngoser. Melihat dari motif gerak yang erotis dari tari Ngoser membuat sang pencipta tari ini yang bernama Susiati, S.Sn (yang lebih akrab dipanggil Susi Hanan Fadila) yang merupakan lulusan ISI Solo Jurusan tari 2006 ingin menggarap tari yang lebih bisa dekat dengan semua kalangan. Hal ini dikarenakan tari Ngoser pada awalnya memang menarik masyarakat namun beberapa kalangan merasa kurang setuju karena menilai tarian tersebut masih dikatakan erotis

Lejeg yang berarti Lengger Jejeg atau Lengger Tegak. Gerakan yang terdapat pada tarian ini patah-patah/ tegas dan berkolaborasi dengan geolan.
Awal mula tarian ini didasari dari acara peresmian pasar Segamas di daerah Purbalingga tahun 2009. Pada peresmian tersebut dihadiri oleh bupati dan wakil bupati Purbalingga. Dalam penampilan tersebut ditampilkanlah tarian Ngoser. Bupati (Triyono Budi Sasongko) menyambut hangat atas ditampilkannya tarian tersebut, namun berbeda dengan wakil bupati (Heru) yang merasa kurang nyaman dengan adanya tarian tersebut. Hal ini diketahui oleh Susiati selaku koreografer tari tersebut dan membuat dia untuk kembali menciptakan tarian yang bisa diterima oleh banyak kalangan.

Setelah mengalami beberapa proses yang lama kurang lebih 2 minggu, susiati mulai melakukan eksplorasi. Hasilnya adalah dia ingin menggarap tarian yang berakar dari tari ngoser namun gerakan lebih dipertegas dan bersifat patah-patah atau dengan kata lain jejeg. Tak jarang demi memperoleh suasana yang mendukung terkadang Susiati ini mencari lokasi yang pas dan tepat untuk mencari rasa dari tarian tersebut. Kurang lebih dalam waktu 10 hari didapatlah gerak untuk tarian ini atas dasar dari beberapa tahap eksplorasi yang telah ia lakukan. Untuk 4 hari berikutnya ia menggabungkan dengan musik. Sang penata iringan yang dia percayai adalah Wendo (suami Susiati yang merupakan lulusan ISI Solo jurusan karawitan) yang berusaha menata iringan sedemikian rupa sehingga didapati iringan yang dapat diperdengarkan sampai saat ini.

Adapun jenis musik yang dipakai adalah moti- motif musik iringan tari Lenggasor diambil dari yang sudah ada antaralain (a) Ilo gondang (yang pada awalnya renggong garut. Diganti karena tempo kurang sesuai), (b) Renggong manis atau gendhing Dangdutan (c) Kuluh kuluh (Baladewanan) untuk gerak gagah.

\section{Perkembangan Lejeg Menjadi Tari Lengganis atau Lenggasor}

Seiring berjalannya waktu, tarian ini kerap kali mengundang komentar dari beberapa masyarakat dari namanya bahwa nama Lejeg di masyarakat biasanya dikenal dengan istilah 
rusak. Kemudian koreografer berinisiatif untuk merubah nama tarian ini dari Lejeg yaitu Lengger Jejeg menjadi Lengganis (Lengger Manis) atau Lenggasor (Lenggah nang ngisor, maknanya menghormati Tuhan, orang tua dan menghargai orang lain). Namun dari masyarakat sendiri sering menyebut tari ini Lenggasor sehingga masyarakat hanya tau istilah Lenggasor. Perubahan ini tidak mempengaruhi jenis ragam gerak yang sudah ada.

\section{Perkembangan Gerak Tari}

Lenggasor awal mula dipentaskan dalam acara pesta rakyat Purbalingga. Dalam pementasan yang pertama masih membuat tanda tanya pada masyarakat karena masih terkesan asing, namun setelah sering dipentaskan lama kelamaan tarian ini mulai banyak disukai masyarakat sehingga mampu menjadi primadona di masyarakat Purbalingga. Untuk gerak tari Lenggasor banyak menggunakan model patah-patah dan mengurangi gerak geolan, kemudian lebih memvariasi pola lantai dan arah hadap.

\section{Perkembangan Musik}

Musik yang dipakai awal mula menggunakan calung tanpa campuran gamelan. Untuk membuat supaya dinamis dan tekanan pada iringan ini, adalah kendang yang mampu membuat penari lebih semangat. Pada awalnya iringan kendang (oleh Wendo) masih biasa-biasa saja. Namun atas permintaan dari koreografer yang menghendaki ada sisipan gerak baru membuat wendo sang penata iringan membuat variasi baru untuk suara atau pukulan kendang agar menjadi lebih hidup..

\section{Perkembangan Tata rias dan Kostum}

Kostum yang dipakai pada awal mula untuk atasan menggunakan garuda, melati, sampur dan jamang. Lalu baju mengenakan mekak oren, dan bawahan kain batik yang dicangcut. Namun perkembangan terjadi saat sebelum pentas di Jawa Tengah, untuk aksesoris kepala oleh penata rias terkadang seringkali ditambah aksen hiasan yang berbeda seperti daun, agar tidak membuat bosan penonton. Namun sebenarnya pemasangan daun di kepala itu bukan merupakan kehendak sang penata tari (Susiati). Dan ciri khas busana warna oren diganti dengan warna biru. Hal ini dilakukan oleh sang penata rias dan busana (asisten susi) agar kostum tidak sama terus seperti kostumkostum pada pementasan sebelumnya. Namun kostum tari Lenggasor yang sebenarnya yang memakai warna oren dengan hiasan kepala hanya garuda, melati, sampur, dan jamang.

\section{Bentuk Penyajian secara keseluruhan}

Hal ini didukung dengan pendapat Jacqueline Smith terjemahan Ben Suharto dalam bukunya Komposisi Tari Sebuah Petunjuk Praktis Bagi Guru yang menjelaskan bahwa bentuk dapat didefinisikan sebagai hasil pernyataan berbagai macam elemen yangg didapatkan secara kolektif melalui vitalitas estetis sehingga hanya dalam pengertian inilah elemen-elemen tersebut dihayati.

Dari pernyataan tersebut dapat diartikan bahwa bentuk merupakan seuatu yang nyata dan beruwujud dapat dilihat, memiliki rupa dari hal-hal yang terkecil, rumit, dan perpaduan dari beberapa unsur atau elemen dengan mempertimbangkan berbagai faktor.

Menurut Purwodarminto dalam KBBI (1985:862) penyajian adalah cara menyampaikan, menghidangkan, menyajikan atau dengan kata lain pengaturan penampilan. Apabila digabungkan menjadi satu kata bentuk penyajian adalah sesuatu yang berwujud, berupa dan teratur yang ditampilkan atau digelar serta dapat dilihat, dirasakan dan dinikmati oleh orang lain yang akhirnya memberikan kepuasan bagi penontonnya. Bentuk penyajian dalam tari terdiri dari gabungan atau perpaduan dari elemen-elem sebagai berikut: (1) Gerak, (2) Musik/iringan tari, (3) tata rias, (4) Tata busana, (5) desain lantai, (6) tempat pertunjukan dan (7) properti tari.

\section{Gerak Tari}

Bahan baku dari tari adalah gerak anggota tubuh yang telah disusun atau ditata melalui berbagai pertimbangan sehingga menjadi 
rangkaian dan wujud ragam yang selanjutnya akan menjadi sebuah gerak tari. Secara umum yang dinamakan gerak adalah perpindahan dari titik atau pose yang satu ke titik yang lain. Seorang koreografer sekaligus seniman besar dan pelukis bathik yang tidak asing lagi pda dunia tari yaitu Bagong Kusudiardjo (1992:6) mengatakan bahwa dalam tari memiliki sifat antaralain: (a) Gerak realistik adalah gerak yang tampak dalam kehidupan sehari-hari, (b) gerak steriring atau besutan yaitu gerak penghubung antara ragam satu menuju ragam berikutnya, (c) gerak simbolik yaitu gerak yang menggambarkan sesuatu baik itu benda, hewan maupun tumbuhan, (d) gerak abstrak yaitu gerak yang tidak menggambarkan sesuatu dan hanya mementingkan keindahan, (e) gerak lambat yaitu gerak yang dilakukan dengan ketukan, atau tempo lambat atau pelan, (f) Gerak cepat yaitu gerak yang dilakukan dengan ketukan atau tempo yang cepat, (g) gerak lemah yaitu gerakan-gerakan kecil yang dilakukan dengan menggunakan tekanan-tekanan gerak, (h) gerak tegang yaitu gerak yang dilakukan dengan menggunakan tekanan-tekanan dan terlihat kaku, (i) gerak lembut yaitu gerak yang dilakukan secara mengalir, (j) gerak agal atau kasar yaitu gerak yang dilakukan menggunakan tekanan-tekanan yangtampak jelas.

Dalam tari Lenggasor sang koreografer dalam menyusun gerak yang disajikan sudah banyak dan komplit dari mulai yang lembut, mengalir, lambat, cepat, maupun yang lainnya sehingga menjadi lebih hidup dan menarik untuk disaksikan. Bagian awal banyak kita lihat menggunakan gerakan yang lembut dan tegas yaitu pada saat jalan, kemudian duduk timpuh kemudian gerakan bahu dan kepala mengikuti iringan musiknya. Pada bagian tengah atau inti disajikan gerakan-gerakan yang cukup variatif, ditambah dengan berbagai pola lantai, arah hadap dan permainan level sehingga penonton tidak merasa bosan, tidak monoton artinya penyajian menjadi hidup dan atraktif. Pada bagian akhir koreografer menyajikan gerak tari putra atau gagahan, gerakan cepat, volume yang lebar pada sikap kaki dan tangan serta angkatan kaki yang tinggi.
Hal ini semua untuk mengikuti konsep dari seni Lengger yang dalam bentuk penyajiannya terdiri dari tiga bagian yaitu bagian awal yaitu gambyongan, bagian kedua adalah badutan dan ebeg-ebegan serta bagian akhir yaitu babak Baladewan.

\section{Iringan Tari}

Tari dan musik merupakan parner yang tidak dapat dipisahkan keberadaannya, tari tanpa musik akan terasa hambar dan membosankan tetapi musiknya monoton juga akan membosankan sehingga musik yang mengiringi tari juga harus digarp atau dirancang memiliki dinamika. Ada dua sumber dan bentuk musik yang dapat mengiringi tari yaitu musik internal dan musik eksternal. Musik internal yaitu musik atau bunyi yang dihasilkan dari diri manusia itu sendiri seperti tepukan tangan, nyanyian, hentakan kaki, terakan, bersiul. Selanjutnya musik eksternal yaitu music atau bunyi yang dihasilkan dari luar anggota badan/tubuh manusia tepatnya dari alat atau instrument misalnya, gamelan, biola, gitar, rebana, siter atau kecapi, calung, angklung, dan sebagainya.

Dalam penyajiannya tari Lenggasor mengunakan instrument music calung dan bisa juga menggunakan gamelan atau karawitan namun pada pelaksanaannya lebih banyak dan sering menggunakan karawitan calung. Hal ini lebih menambah nuansa atau warna khas Banyumasan, dan dari sisi alat atau intrumennya lebih unik dan menarik bagi orang yang menyaksikan serta merasakan bunyi calung tersebut.

\section{Tata Rias dan Kostum}

Komponen tata rias dan kostum merupakan hal yang penting dan sangat mendukung penampilan atau penyajian sebuah tari atau kesenian, pemain akan menjadi lebiah menarik dan jelas apabila mereka menggunakan pendukung rias dan ksontumnya. Tata rias merupakan seni menggunakan bahan kosmetik untuk merubah wajah seseorang menjadi lebih cantik, gagah, bagus, jelek, jahat, baik, dari aslinya. Sedangkan kostum yaitu segala 
atau semua sandangan atau asesoris yang digunakan atau menempel di badan seseorang untuk memperjelas tokoh, peran, karakter dan menunjukan, daerah asal tarian itu sendiri. Untuk tari Lenggasor karena merupakan tari putri maka menggunakan tata rias panggung, rias cantik walaupun pada bagian akhir menarikan gerakan gagahan atu putra.

\section{Tempat Pertunjukan}

Dalam seni pertunjukan apapun tempat atau playing area menjadi sangat penting keberadaannya, karena keberhasilan, kesuksesan dan tempat yang memadai memiliki peran yang tidak dapat diabaikan. Sekecil dan seluas apapun, bentuk yang sederhana sampai dengan yang modern, di dalam gedung maupun dluar gedung tidak menjadi permasalahan dalam sebuah pertujukan kesenian khususnya tari. Halaman rumah, tanah lapang, pendopo, joglo, dalam bentuk arena terbuka kemudian, jalan beraspal maupun konblok atau diatas tanah basah dan kering, bukit atu di tepi sungai atau kolam, sawah yang berlumpur sekaligus dapat menjadi tempat yang menarik.

Perkembangan menurut Sedyawati dalam Suwandono (1939: 39), menyatakan bahwa: Perkembangan mempunyai arti pengolahan, berdasarkan unsur-unsur tradisi yang diberi nafas baru sesuai dengan tingkat perkembangan masa tanpa mengurangi atau menghilangkan nilai-nilai tradisi. Selanjutnya Sedyawati (1981: 50), Perkembangan mempunyai arti pembesaran volume penyajian atau perluasan wilayah, pengenalan, memperbanyak tersedianya kemungkinan-kemungkinan untuk mengolah dan memperbaharui wajah suatu usaha yang mempunyai arti sebagai sarana untuk timbulnya pencapaian kreativitas. Pendapat dari Ahmadi (2005: 1) Perkembangan merupakan suatu perubahan secara bertahap dengan tujuan menyempurnakan atau menuju hasil yang lebih baik sesuai situasi dan kondisi yang bersifat tetap dan maju

Sesuai dengan berbagai pendapat maka dapat disimpulkan bahwa perkembangan bentuk penyajian adalah perubahan atau perluasan melalui wujud ungkapan atau penampilan sehingga menjadi lebih baik, menarik dan memuaskan penikmatnya atau penontonnya. Demikian juga dengan bentuk penyajian tari Lenggasor, di sini sang koreografer selalu berupaya semaksimal mungkin untuk menyiapkan unsur-unsur pendukungnya dan menyiapkan segala sesuatunya agar tampil dengan baik dan pemirsa merasa senang dan puas.

Bentuk penyajian tari Lenggasor pada tahun 2006, ditarikan oleh 6 orang penari atau kelompok kecil, hal ini dipersiapkan untuk penampilan di gedung atau panggung pertunjukan bahkan untukmengikuti lombaatau festival tari. Perkembangan selanjutnya pada tahun 2009 tari Lenggasor diberi kesempatan untuk tampil secara masala tau dalam jumlah banyak untuk acara pembukaan peresmian pasar Purbalingga yang berskala besar.

Selanjutnya dapat kami laporkan berdasarkan kajian dan wawancara dengan beberapa mahasiswa dan melihat di Youtube bahwa tari Lenggasor dimintai oleh beberapa Unit Kegiatan Mahasiswa (UKM) di Perguruan Tinggi. Mereka belajar tarian Lenggasor ada yang kebetulan mahasiswa tersebut dapat menari dari daerah asalnya yaitu Banyumas dan ada yang mendatangkan pelatih yang mampu menari tarian tersebut.

Dari berbagai kegiatan yang terselenggara dan dilakukan oleh masyarakat otomatis akan ada perkembangan bentuk penyajian dalam pengolahan pola lantai, level, arah hadap, tempat pertunjukan dan gerak yang lebih atraktif serta tata rias serta busananya.

\section{KESIMPULAN}

Tari Lenggasor merupakan jenis tari kerakyatan yang bercirikhas Banyumasan, dan merupakan pengembangan dari tari Lengger. Tarian ini diciptakan oleh Susiati, S.Sn. alumni ISI Surakarta sekaligus putra daerah Purbalingga Banyumas Jawa Tengah pada tahun 2006. Proses kreatif yang dilakukan dalam mencipta tari Lenggasor melalui tahapan eksplorasi, Improvisasi, evaluasi dan Forming atau komposisi. Pada tahun 2009 tari Lenggasor dipentaskan pertama kali pada 
acara peresmian pasar besar pemda kabupaten Purbalingga dengan penari masal.

Selanjutnya tarian ini diminta mewakili Purbalingga untuk mengikuti lomba tari dan parade tari daerah baik di tingkat provinsi dan Nasional di Jakarta. Selanjutnya dalam perjalanan waktu tari Lenggasor banyak diminati dan disukai oleh masyarakat sehingga mengalami perubahan dengan pemendekan durasi waktu pentas, pemadatan ragam gerak, kostum yang lebih bagus/menarik, dan desain lantai yang variatif, serta iringan yang lebih dinamis.

\section{DAFTAR PUSTAKA}

Ahmadi Abu. 2005. Psikologi Perkembangan. PT. Rieneka Cipta

Bagong K. 1981. Tentang Tari. Yogyakarta: Nur Cahaya
Hadi, Sumandyo. 2012. Koreografi, Bentuk dan Isi. Cetakan ke II, Yogyakarta: Cipta Media.

Hawkins, Alma. 1979. Mencipta lewat Tari. Terjemahan Y Sumandyohadi. Yogyakarta: Manthili.

Moleong Lexy J. 1996. Metode Penelitian Kualitatif. Bandung: PT. Remaja Rosda Karya

Murgiyanto Sal. 1985. Koreografi. Jakarta.

Sedyawati Edi. 1979. Tari Tinjauan dari berbagai segi. Jakarta: Pustaka Jaya / 1981.Pertumbuhan Seni Pertunjukan Indonesia. Jakarta, Sinar Harapan.

Smith Jacqueline. 1985. Komposisi Tari Sebuah Petunjuk Praktis Bagi Guru. (terjemahan Ben Suharto, S.S.T) Yogyakarta: Ikalasti

\section{LAMPIRAN}

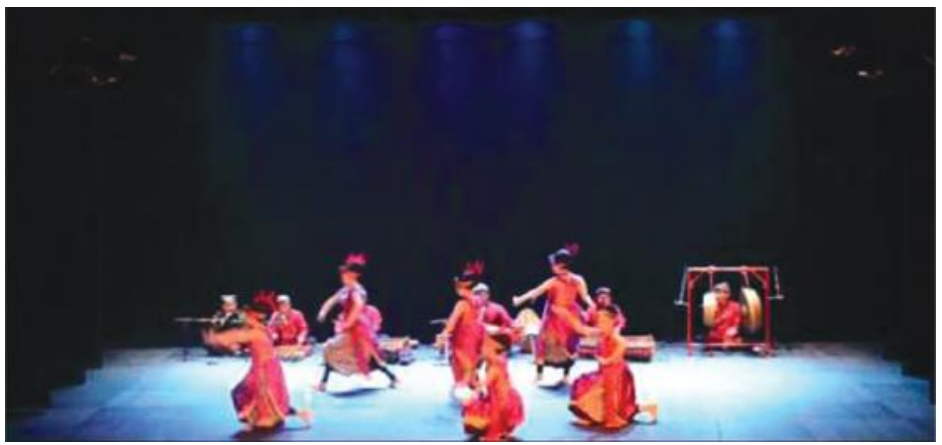

Pentas Tari Lenggasor

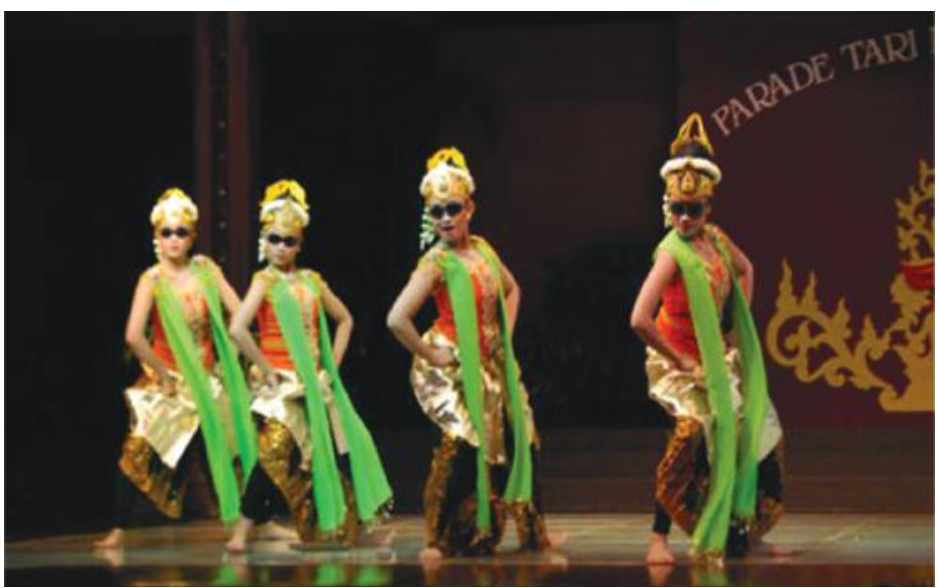

Pentas Tari Lenggasor 